\title{
Managing the unmet psychosocial and information needs of patients with cancer
}

This article was published in the following Dove Press journal:

Patient Intelligence

19 November 2010

Number of times this article has been viewed

\author{
Kathleen Abrahamson' \\ Morgan Durham' \\ Rebekah Fox ${ }^{2}$ \\ 'Department of Public Health, \\ Western Kentucky University, \\ Bowling Green, KY, USA; \\ ${ }^{2}$ Department of Communication, \\ Texas State University, San Marcos, \\ TX, USA
}

\begin{abstract}
In this article, we synthesize current literature regarding the unmet needs of cancer patients, with a specific focus on interventions that address psychosocial distress, social support, and information deficits. Research indicates many patients diagnosed with cancer express unmet needs in terms of emotional distress, decision-making support, and practical concerns such as childcare, transportation, and financial assistance. Four types of system-level barriers to the meeting of patient psychosocial and information-based needs emerge from the literature: underidentification of needs due to inadequate assessment, time constraints on cancer care providers, lack of adequate reimbursement for psychosocial and information services, and barriers related to communication of disease-related information. There is also evidence that unmet need, especially unmet information need, is related to the level of patient health literacy. Patient empowerment through the resolution of unmet needs increases patient participation in care, and is especially crucial in regards to understanding risks and benefits of treatment. There is evidence that some interventions are effective for some patients, and that even relatively simple interventions can reduce psychosocial and information-based needs. The challenge is therefore to discover which intervention will be effective for each individual patient, and to attain the skills and resources necessary to intervene appropriately.
\end{abstract}

Keywords: cancer, unmet need, health literacy, intervention

\section{Introduction}

The US National Cancer Institute estimates that 1,529,560 Americans will be diagnosed with an invasive cancer and 569,490 Americans will die from cancer in 2010. Importantly, 11 million Americans are currently living with cancer, either as a posttreatment survivor, while receiving active treatment, or in a palliative care situation. ${ }^{1,2}$ The experience of cancer patients is widely varied. However, previous research indicates many patients diagnosed with cancer express unmet needs in terms of emotional distress, decision-making support, and practical concerns such as childcare, transportation, and financial assistance. ${ }^{3-6}$ The following question emerges: Given the complex nature of cancer and cancer treatment, how are the psychosocial and information needs of cancer patients addressed in settings where clinical outcomes are the priority? In this article, we summarize current literature regarding the unmet needs of cancer patients, with a specific focus on interventions that address psychosocial distress, social support, and information deficits. Searches were conducted through PubMed and Scopus using the keywords cancer in conjunction with psychosocial distress, unmet need, health literacy, and social support. Articles were also identified through the cited works of relevant articles, with a focus on identifying both review and original research articles that
Correspondence: Kathleen Abrahamson Department of Public Health, WKU, 1906 College Heights Blvd.\#I I082, Bowling Green, KY 4210I-1082, USA Tel +l 2707456973

Fax +I 2707454437

Email kathleen.abrahamson@wku.edu 
address psychosocial and information-based interventions from the perspective of unmet need.

\section{Prevalence of unmet need}

Within the context of cancer treatment, needs are defined as resources necessary for patients and families to live and function with a diagnosis of cancer. ${ }^{7}$ Of importance is the prevalence of need which remains unmet by either the health services system or informal caregiving networks. Some unmet needs are practical, such as the need for parking at clinics, money for travel to and from appointments, and accurate information regarding the disease process. ${ }^{6}$ Other unmet needs are more complex: daily assistance with functional activities such as home maintenance and personal care, psychological symptoms such as depression and anxiety, and information regarding treatment risks and decision making. ${ }^{7}$ The psychosocial and information needs of cancer patients and survivors that frequently go unmet are the focus of this review.

Psychosocial and information needs are prevalent among cancer patients. In an examination of urban women with breast cancer, Aranda et $a l^{8}$ found that more than $20 \%$ of the sample had a high level of psychological and informationbased need. The two most frequent areas of unmet need were managing worries about the stress experienced by significant others and the desire for additional information about keeping oneself well. Also common were fear of the future, lack of a health care provider to talk to, and the pragmatic concern of inadequate parking for clinic appointments. ${ }^{8}$ Beesley et $\mathrm{al}^{9}$ found that more than $40 \%$ of gynecological cancer patients had psychosocial needs including worries and fears that were not currently being alleviated by health care providers. Graves et $\mathrm{al}^{10}$ noted $61 \%$ of patients screened in a multidisciplinary lung cancer clinic reported a clinically significant level of psychosocial distress, and information problems were a significant predictor of distress. Both Sanson-Fisher et $\mathrm{al}^{6}$ and McDowell et $\mathrm{al}^{5}$ also found that cancer patients had unmet needs, including needs for further disease-related information and psychological concerns.

Research indicates that needs of cancer patients are highly variable and continue through the active treatment period into survivorship..$^{7,8,11,12}$ Risk of unmet need has been related to age, gender, education, income, geographic location, diagnosis, and marital status. Specifically, female patients, patients with low socioeconomic status, patients diagnosed at a young age, patients with a poor prognosis and/or not in remission, patients who lack a spouse or significant form of social support, patients who live in remote settings, and patients with a history of anxiety and/or depression are at most risk for having a high level of need that remains unmet. ${ }^{5,9,13-17}$ However, level of patient need is often not well predicted by demographic factors alone, and assumptions about need should be avoided when addressing the needs of individual cancer patients. ${ }^{8}$

Although level of need changes over the course of cancer treatment, patient needs may be high at the beginning of treatment and after treatment concludes. ${ }^{18}$ In a systematic review of research addressing the unmet needs of cancer patients, Harrison et $\mathrm{al}^{7}$ found the highest level of need at the time of initial treatment, but the greatest number of individual patients expressed at least some need at treatment's end. The conclusion of treatment results in less-frequent interaction with the health services system, and perhaps a feeling of disengagement from the reassurance of health care providers. Because patients are seen less often, once treatment concludes the risk of needs going unidentified is even greater. However, research has mainly focused on patients in active treatment phases, or brief $(<1$ year $)$ time frames posttreatment. A focus on cancer survivorship shifts attention from mortality to morbidity, including psychosocial morbidity. Psychosocial morbidity has not yet been well addressed by the episode-focused system of cancer care delivery. ${ }^{8,19}$ There is evidence that needs change and at times expand up to 3 years posttreatment, therefore necessitating the extension of psychosocial and information interventions into cancer survivorship. ${ }^{5,19-21}$

Although it is clear that certain populations are at greater risk, the level of unmet need and predictors of unmet need are highly variable among individuals. Because need is a complex concept, research has not provided consistent, clear information concerning who suffers from unmet need. This is in part due to inconsistent research methods in terms of sampling strategies and measurement of need, as well as the heterogeneous nature of cancer and cancer patients. ${ }^{78}$ Although the predictors of need are variable, research indicates that cancer patients who have a high level of psychosocial and/or information need are at high risk of having those needs remain unmet by the current system of cancer care delivery. ${ }^{5,12}$

\section{Barriers to meeting patient needs}

After careful consideration of the literature, we identify four types of system-level barriers to the meeting of patient psychosocial and information-based needs as emergent from the literature: underidentification of needs due to inadequate assessment, time constraints on cancer care providers, lack of adequate reimbursement for psychosocial 
and information services, and lack of appropriate and available information. First, need often goes unrecognized by health care providers. ${ }^{5,12}$ Patients express reluctance to share emotion-based information with doctors, and without routine assessment of psychosocial and information needs by providers upon admission and at times of change in treatment, it is challenging for providers to accurately determine what needs patients have and develop strategies to meet those needs. ${ }^{11}$ Without a cancer care system that provides adequate psychosocial assessment of all patients, needs may remain unidentified and unaddressed until a sense of trust is developed with providers, or patients are able to identify and articulate their own needs. ${ }^{22}$

Second, cancer care providers work within scheduling constraints and often lack the time to fully address psychosocial or information-based needs. Cancer clinics are busy places, and the reliance upon outpatient care for much cancer treatment further limits the time available for providers and patients to discuss the challenges they are facing. ${ }^{14,23,24}$ Providers frequently miss subtle clues of need, and identification of psychological need may be further complicated by the similarity between treatment side effects such as fatigue and lack of concentration and the signs of psychological distress. ${ }^{4,25}$ As was noted earlier, clinical settings may lack the time and tools to perform proper assessment. Time to allow patients structured opportunities to provide subjective accounts of their experience with cancer to providers could potentially reduce the level of unmet psychological and information-based needs. ${ }^{12,26}$

Third, reimbursement for psychosocial or informationbased intervention continues to be a challenge, and often forms a barrier to the elimination of patient need. Reimbursement is especially challenging in survivorship, when needs may increase but there is often little ability to charge for supplemental services related to a past cancer diagnosis. ${ }^{21,27}$ Informal caregivers also have unmet needs and may struggle to find reimbursement to attain necessary services. This is especially true for caregivers with poor health and low social support. ${ }^{28}$ Caregiver needs are at additional risk of going unaddressed if the method of assessment of caregiver burden is to ask the patient to estimate their caregiver's needs. Sharpe et $\mathrm{al}^{28}$ found patients estimate that they require a significantly lower level of care than caregivers estimate they give, and caregiver burden is predicted by a large discrepancy between patient and caregiver estimation of a patient's required care needs.

Lastly, materials that provide information in a manner which is understandable and age appropriate may not be readily available to patients. Patients who are diagnosed when they are young may experience greater unmet needs due to lack of age-appropriate information material and interventions. The needs of patients diagnosed at young ages (primarily adults below age 40) differ in terms of social responsibilities, developmental/life course issues, and a desire to participate in care. Although it is unclear from the current literature if the failure to meet the needs of patients younger than 40 years is due to a lack of available age-appropriate materials or the inability of the cancer care providers to access and deliver those materials, it is clear that patients diagnosed at a younger age have additional needs that are currently unmet. Zebrack ${ }^{29}$ found $97 \%$ of cancer patients younger than 40 years had a desire for information to direct or participate in care decisions, and $50 \%$ of those who desired information indicated that their need for information remained unmet. Sixty percent of those younger than 40 years who were sampled desired additional assistance with psychosocial issues. Conversely, Hurria et $\mathrm{al}^{30}$ found $41 \%$ of sampled cancer patients aged between 65 and 95 years had significant levels of distress, primarily related to declines in functional ability. For patients of all ages, issues of spirituality and sexuality related to cancer treatment are not well researched. Young patients, especially young women, have been identified as being most likely to experience psychosocial needs related to sexuality. ${ }^{6}$ Level of patient health literacy is a significant concern in regards to the management of information-based need, and is discussed further in the section that follows.

\section{The role of health literacy}

There is research evidence that unmet need, especially unmet information need, is related to level of patient health literacy. In the report 'Healthy People 2010', the US Department of Health and Human Services defined health literacy as 'the degree to which individuals have the capacity to obtain, process, and understand basic health information and services needed to make the appropriate health decisions'. ${ }^{31}$ This capacity to obtain, process, and understand includes the ability to process both written and verbal communication. The definition of low health literacy varies, and is confounded by the finding that general literacy levels may not correlate with an individual's health literacy. Even those patients with high levels of education and/or a moderately high level of general literacy may struggle to comprehend the jargoned and diseasespecific information provided in health care settings. ${ }^{32}$

Low health literacy is prevalent in the US health services system. Although the definition of low health literacy varies between health care contexts, it is estimated that between $20 \%$ and $40 \%$ of Americans struggle to adequately 
comprehend health care information. ${ }^{32,33}$ Lindau et $\mathrm{al}^{34}$ found $40 \%$ of women who presented for routine cervical cancer screening had a low level of health literacy, and that level of health literacy related closely with disease-related knowledge. Levels of health literacy in the United States tend to be lower in public health settings, among those who have English as a second language when information is presented only in English, among those with low levels of formal education, and among patients of advanced age. ${ }^{32,33}$ However, much like estimating levels of unmet needs, assumptions about an individual patient's health literacy level cannot be made by examining demographic characteristics.

Health literacy is a particular challenge in complex and ongoing disease states such as cancer. ${ }^{32,33}$ Even patients with moderate levels of general literacy may struggle to comprehend terms such as tumor, lesion, colonoscopy, metastasis, or malignant. ${ }^{32}$ A patient's ability to process information can influence patient participation in care, assessment of risk, understanding of screening and treatment, and even health outcomes. In fact, Baker et $\mathrm{al}^{35}$ found that health literacy independently predicted mortality in a population of elderly Medicare recipients, even while accounting for socioeconomic status and level of education.

Even when information is thoroughly and readily provided when needed, retention of information is often a struggle. Overall, most patients are able to recall only $50 \%$ of the information they are presented. ${ }^{36,37}$ Schillinger et $\mathrm{al}^{37}$ found physician assessment of patient recall and understanding of disease-related information improved not only retention of information, but clinical outcomes as well. It is important, however, for providers to determine the emotional and psychological effect the information being communicated might have. If patients are receiving startling or difficult information, which may frequently be the case in cancer care, they may not be able to comprehend and recall information at the same level that an assessment of health literacy would indicate. Techniques such as scheduling a second appointment to assess recall and providing supplementary written materials may be helpful. ${ }^{38}$

Without a structured assessment of health literacy upon admission, the ability to determine health literacy levels in a clinical setting requires excellent provider communication skills and some degree of intuition. ${ }^{32}$ Lindau et $\mathrm{al}^{34}$ found physicians were able to identify only the very lowest of literacy abilities, missing the majority of patients with unmet information needs. Active efforts to assess health literacy are especially important for populations that have been found to have a high level of unmet information needs, in particular patients with advanced cancer and patients getting a combination of treatments or complicated treatment regimens. ${ }^{6}$ Information needs may also increase posttreatment into survivorship as patients have less frequent contact with health care providers. ${ }^{5}$ Because it is challenging to assess health literacy in busy clinical settings, the most effective approach may be to provide information in its simplest, most usable form and assess understanding and recall for all cancer patients, not just those with significant risk factors. ${ }^{33}$

\section{Health literacy and risk-benefit information}

Information presented in a risk-benefit format is common in health literature, but because it is often based on complicated quantitative formulas and frequently does not take into account the individual's specific experience, the risks and benefits associated with a particular treatment can be difficult for even those with high levels of health literacy to understand. ${ }^{33,39}$ As diagnostic testing becomes better able to predict individual risk, the need to communicate risk-benefit information clearly will increase. ${ }^{39}$ It is not uncommon for patients' perceptions of a medical condition like cancer, how it begins, evolves and is treated, to differ appreciably from the perceptions and recommendations of health care providers. Individuals may experience a unique type of anxiety when the risk information involves genetic screening, or the potential for one's children to share in adverse health outcomes. ${ }^{40}$

Anxiety regarding individual risk and cancer treatment is common, but patients are more likely to participate in decisions about cancer treatment if they are confident they understand the risk-benefit information provided by clinicians. ${ }^{41}$ Lillie et $\mathrm{al}^{42}$ found those with low health literacy who underwent genomic testing for breast cancer recalled less information and wanted less input in decision making than high-literacy patients, but were equally likely as those with high literacy to desire more information. Patients with low health literacy are therefore less likely to participate actively in their own care and more at risk to have their need for further information remain unmet. Those with low health literacy are also more likely than those who are better equipped to comprehend risk-based information to rely on friends and family for assistance with treatment decisions and believe information that is inaccurate. ${ }^{32}$ It is difficult to make a good decision about your treatment when you don't understand the risk. ${ }^{32,33}$

Health literacy has greater potential to effect decision making regarding treatment than it does in effecting compliance with cancer screening in primary care settings. ${ }^{34,43}$ 
Patients with low health literacy may present for an annual exam, but are at risk of not fully comprehending the risks and benefits of treatment choices if test results require further action, and are therefore at risk of making choices that do not truly reflect their needs. ${ }^{32,33}$ Patients express a desire to receive risk information that is specific to their individual situation to understand personalized risk. ${ }^{44}$ Forms of communication that supplement the patient-physician verbal encounter such as having patients watch videos featuring the personal narratives of individuals have been found effective in communicating complicated cancer care information to low-health-literacy populations. ${ }^{32}$ Unfortunately, evidencebased communication practices that allow for assessment of learning and nonverbal techniques are not consistently implemented. Schwartzberg et $\mathrm{al}^{45}$ found that when providers need to communicate complicated information, they often use strategies such as simplifying language, speaking loudly, and speaking slowly more frequently than the recommended strategies of teach-back techniques and frequent learning assessments, often with less-than-satisfactory results.

\section{Patient-centered care}

Patient empowerment through meeting information needs leads to patient participation. Barriers such as a patient's hesitancy to ask questions, fear of the unknown, low self-confidence, or the tendency of providers to overtake consultations may prevent patients from expressing need. However, providers can take steps to increase the quality of communication exchanges by using probing questions, providing reassurance, increasing the availability of written information, following up to assess understanding, and designing care around individual patient needs. ${ }^{46}$ A conceptualization of cancer care that embodies this philosophy is patient-centered care (PCC), or care that is individualized and sensitive to the elevation of suffering that results when patient needs go unmet. PCC serves patient needs before the needs of health care systems and providers. ${ }^{41}$ In relation to unmet psychosocial and information needs of cancer patients, PCC can be described as integrating patient-provider communication, continuity, and concordance in order to reduce patient vulnerability and minimize suffering. ${ }^{41,47}$

Unmet psychosocial needs may negatively influence patient participation in clinical decision making and adherence with courses of treatment once they are initiated. ${ }^{14}$ There is evidence that populations most at risk for unmet needs in terms of low health literacy and high psychosocial distress are also likely to achieve benefit from PCC, and that simple interventions can be effective. ${ }^{41}$ For example, a simple, brief orientation to clinical processes was found to reduce the stress levels of cancer patients. ${ }^{48}$ Street et $\mathrm{al}^{49}$ found that providing information and training about discussing pain with providers resulted in patients asking more questions of providers and being more assertive about their pain management needs. In case study examinations of clinics that were able to achieve high screening rates for colorectal cancer, Nemeth et $\mathrm{al}^{50}$ found communication with patients in the form of frequent reminders, assistance navigating the health care system, and use of electronic tools to manage patient information were key components to clinical success. There is evidence that both patient and provider satisfaction increases with the use of patient-centered techniques. ${ }^{41}$

A significant barrier to a patient-centered approach occurs when providers assess needs differently to patients either by underestimating or overestimating their needs. Dissimilar assessment of needs is of particular importance when patients have communication difficulties or high levels of information-based needs. ${ }^{41}$ For example, PCC advocates for the inclusion of subjective measures to assure patient participation in needs assessment. This is challenging, however, when patients are overwhelmed, underinformed, and unable to identify their own needs. They often don't know what services are out there to request, or what is causing their feelings of distress. ${ }^{12}$

There is evidence that cancer patients perceive physicians to be unable to or uninterested in discussing psychosocial issues. $^{25,38}$ PCC requires health care providers to have the ability to interact with patients in a manner that assures information is understood by the patient, especially during those encounters that involve clinical decision making. However, patients may desire information about their diagnosis and prognosis without wishing to take an active role in clinical decision making, a wish that should be respected if approaching care from a patient-centered perspective. ${ }^{41}$ Organizations with shared governance structures and high levels of provider autonomy are more likely to implement patient-centered techniques. However, it must be noted that our current system of cancer care delivery is based on episodic interactions with providers and the management of physical outcomes; thus, true PCC is only rarely wholly achieved. ${ }^{47}$

\section{Effectiveness of current interventions}

Research on the effectiveness of interventions to eliminate unmet patient needs in cancer has yielded mixed results. ${ }^{21,51,52}$ In the absence of concrete direction from research and adequate resources such as time and need assessment instruments, 
providers regularly address patient need informally through relatively simple interventions including active listening and attempting to develop a trusting relationship with patients. ${ }^{11,18,24,26}$ Even active listening can be enhanced by assessing a patient's psychosocial status and providing physicians with that knowledge. Providing doctors with knowledge of patients' quality of life level increases the ability of a provider to address patient need and increase quality of life indicators. A study involving 286 cancer patients and 28 oncologists found that routinely measuring quality of life and providing oncologists with this information improved overall quality of life outcomes for patients. ${ }^{53}$ Hawkes et $\mathrm{al}^{54}$ assessed the effectiveness of allowing telephone operators at a cancer referral line to use an established distress measurement tool and assess callers for symptoms of distress. They found telephone assessment to be accurate and an effective means of triaging patients to additional services when necessary. Inexpensive interventions such as calming music or relaxation techniques can be effective in alleviating emotional distress as well. ${ }^{55}$ Especially in end-stage cancer patients, setting small daily goals and rehearsing difficult situations have been shown to reduce stress. ${ }^{56}$

The nature of interventions differs greatly as do their effects. Some psychosocial or information-based interventions, or deliberate and planned actions to influence patient outcomes, are highly effective but only for a targeted population. Cancer patients are heterogeneous, and it is important to gear intervention toward the needs of the specific population served..$^{6,7,57}$ For example, Wengstrom et $\mathrm{a}^{58}$ found that a structured nursing intervention designed to reduce unmet psychosocial needs was effective for only those patients aged 59 years and older. Conversely, Ong et al $^{59}$ found audiotaping patient/provider consultations to provide patients with a resource to review instructions had a greater influence on patient satisfaction for patients in younger age groups. For populations with low health literacy, narrative videos or information presented creatively to de-emphasize the listing of facts can be effective in reducing information needs. ${ }^{60}$ Unfortunately, information-focused interventions are too often targeted toward those least at risk for low health literacy, primarily patients who are nonelderly, nonminority, and male. ${ }^{61}$ Spiritual interventions may be effective in overall reduction of patient need, though research results are currently inconclusive. ${ }^{62}$ Some studies have found peer support to be effective, whereas others have shown little reduction in unmet psychosocial or information need from peer-led interventions. ${ }^{63,64}$ In an example of effective peer-driven intervention, Macvean et $\mathrm{al}^{64}$ found training nonclinical volunteers to assist patients in developing strategies to identify and meet unmet needs was both feasible and effective in reducing need level and depression.

Much study of interventions to address unmet psychosocial and information-based needs examines care given within clinical contexts. However, the importance of unmet need in the community setting cannot be overemphasized. Although patients receive clinical treatment within health care settings, much need is identified in the home, workplace, and during survivorship when clinical treatment has ended. ${ }^{9}$

There is evidence that some interventions are effective for some patients; the challenge is in knowing what intervention will be effective for which individual patient. ${ }^{21,51,52}$ Intervention outcomes often do not justify the costs of the intervention, though the lack of significant findings in the literature may be due to methodological inconsistencies as much as intervention ineffectiveness. ${ }^{64-66}$ Although the literature addressing unmet psychosocial and informationbased needs in cancer patients is rapidly expanding, it is difficult for those in active clinical practice settings to condense findings and reach definitive conclusions due to the variety of sampling techniques and analytical methods in the literature..$^{51,66-68}$ There is a need for studies which include samples that are representative of a wider population of cancer patients, have adequate statistical power to determine interventional influence, and follow-up with respondents to measure intervention effectiveness over time. ${ }^{52,68,69}$ More focused study of psychosocial and information needs in men and minorities is needed.$^{67}$ Patients with terminal-stage cancer are particularly understudied, primarily because of the difficulty obtaining adequate sample size, and patient attrition. ${ }^{56}$ Evaluation of interventions designed to reduce unmet patient needs is further complicated by the difficulty in objectively measuring improved overall quality of life. ${ }^{12}$

\section{Conclusions}

Being diagnosed with cancer is a stressful event. There are negative societal connotations of cancer treatment, a cultural affiliation of cancer with death, and the almost unavoidable concern about meeting care and treatment needs. ${ }^{18}$ However, there is evidence that cancer patients experience improved quality of life in some areas, specifically through a process of making meaning out of the more negative or life-threatening aspects of the disease. ${ }^{19,21,27}$ Hodgkinson et al ${ }^{19}$ found that more than $70 \%$ of cancer survivors recalled at least one positive outcome from their cancer experience.

A larger question looms: how much clinical emphasis should be placed on the reduction of unmet need in order to improve overall quality of life, especially in cases where 
physical outcomes may suffer due to time and attention spent addressing the supportive care needs of patients? Past research shows patients were more satisfied with the clinical aspects of their care than with the information and communication they received from providers. ${ }^{6}$ Baseline quality of life is related to survival, and interventions to reduce psychosocial need may positively impact survival, though the evidence remains unclear and the influence of provider efforts to reduce unmet need is also unclear. ${ }^{68,70,71}$ What is clear, however, is that a provider's ability to improve communication quality, provide accurate information, and direct care toward the reduction of patient need results in an improved experience living with a cancer diagnosis. This is especially important for the estimated 25 million cancer survivors and the people who care for them. ${ }^{57,72}$

\section{Disclosure}

The authors report no conflicts of interest in this work.

\section{References}

1. Surveillance, Epidemiology, and End Results (SEER) Program. Prevalence Database: 'US Estimated 31-Year L-D Prevalence Counts on 1/1/2006', National Cancer Institute, Based on the 2008 November SEER Data Submission. Available from: http://www.seer.cancer.gov. Accessed 2010 Aug 28.

2. Surveillance, Epidemiology, and End Results (SEER) Program. SEER Stat Fact Sheets: All Sites. National Cancer Institute, Based on the 2009 November SEER Data Submission. Available from: http://www.seer. cancer.gov. Accessed 2010 Aug 28.

3. Carlson L, Bultz BD. Cancer distress screening: needs, models, and methods. J Psychosom Res. 2003;55(5):403-409.

4. Merckaert I, Libert Y, Delvaux N, et al. Factors that influence physicians' detection of distress in patients with cancer: can a communication skills training program improve physicians' detection? Cancer. 2005;104(2):411-421.

5. McDowell ME, Occhipinti S, Ferguson M, Dunn J, Chambers SK. Predictors of change in unmet supportive care needs in cancer. Psychooncology. 2010;19(5):508-516.

6. Sanson-Fisher R, Girgis A, Boyes A, Bonevski B, Burton L, Cook P. The unmet supportive care needs of patients with cancer. Supportive Care Review Group. Cancer. 2000;88(1):226-237.

7. Harrison JD, Young JM, Price MA, Butow PN, Solomon MJ. What are the unmet supportive care needs of people with cancer? A systematic review. Support Care Cancer. 2009;17(8):1117-1128.

8. Aranda S, Schofield P, Weih L, et al. Mapping the quality of life and unmet needs of urban women with metastatic breast cancer. Eur J Cancer Care (Engl). 2005;14(3):211-222.

9. Beesley V, Eakin E, Steginga S, Aitken J, Dunn J, Battistutta D. Unmet needs of gynaecological cancer survivors: implications for developing community support services. Psychooncology. 2008;17(4): $392-400$

10. Graves KD, Arnold SM, Love CL, Kirsh KL, Moore PG, Passik SD. Distress screening in a multidisciplinary lung cancer clinic: prevalence and predictors of clinically significant distress. Lung Cancer. 2007;55(2):215-224.

11. Botti M, Endacott R, Watts R, Cairns J, Lewis K, Kenny A. Barriers in providing psychosocial support for patients with cancer. Cancer Nurs. 2006;29(4):309-316.

12. Sanson-Fisher R, Carey M, Paul C. Measuring the unmet needs of those with cancer: a critical overview. Cancer Forum. 2009;33(3): 200-203.
13. Leight SB. The application of a vulnerable populations conceptual model to rural health. Public Health Nurs. 2003;20(6):440-448.

14. Clark PM. Treating distress: working toward psychosocial standards for oncology care. Proceedings of the 26th Congress of the Oncology Nursing Society; 2001 May 17-20; San Diego, CA.

15. Cueller N, Butts JB. Caregiver distress: what nurses in rural settings can do to help. Nurs Forum. 1999;34(3):24-30.

16. Kenny A, Endacott R, Botti M, Watts R. Emotional toll: psychosocial care in rural settings for patients with cancer. $J$ Adv Nurs. 2007;60(6):663-672.

17. Simon AE, Thompson MR, Flashman K, Wardle J. Disease stage and psychosocial outcomes in colorectal cancer. Colorectal Dis. 2009;11(1):19-25.

18. Arantzamendi M, Kearney N. The psychological needs of patients receiving chemotherapy: an exploration of nurse perceptions. Eur J Cancer Care (Engl). 2004;13(1):23-31.

19. Hodgkinson K, Butow P, Hunt GE, et al. The development and evaluation of a measure to assess cancer survivors' unmet supportive care needs: the CaSUN (Cancer Survivors' Unmet Needs measure). Psychooncology. 2007;16(9):796-804.

20. Arndt V, Merx H, Stegmaier C, Ziegler H, Brenner H. Restrictions in quality of life in colorectal cancer patients over three years after diagnosis: a population based study. Eur J Cancer. 2006;42(12):1848-1857.

21. Stanton AL. Psychosocial concerns and interventions for cancer survivors. J Clin Oncol. 2006;24(32):5132-5137.

22. Marcus AC, Garrett KM, Kulchak-Rahm A, Barnes D, Dortch W, Juno S. Telephone counseling in psychosocial oncology: a report from the Cancer Information and Counseling Line. Patient Educ Couns. 2002;46(4):267-275.

23. Fulcher CD, Gosselin-Acomb TK. Distress assessment: practice change through guideline implementation. Clin J Oncol Nurs. 2007;11(6):817-821.

24. Madden J. The problem of distress in patients with cancer: more effective assessment. Clin J Oncol Nurs. 2006;10(5):615-619.

25. Ryan H, Schofield P, Cockburn J, et al. How to recognize and manage psychological distress in cancer patients. Eur J Cancer Care (Engl). 2005;14(1):7-15.

26. Honea NJ, Brintnall R, Given B, et al. Putting evidence into practice: nursing assessment and interventions to reduce family caregiver strain and burden. Clin J Oncol Nurs. 2008;12(3):507-516.

27. Holland JC, Reznik I. Pathways for psychosocial care of cancer survivors. Cancer. 2005;104 Suppl 11:S2624-S2637.

28. Sharpe L, Butow P, Smith C, McConnell D, Clarke S. The relationship between available support, unmet needs, and caregiver burden in patients with advanced cancer and their carers. Psychooncology. 2005; 14(2):102-114.

29. Zebrack B. Information and service needs for young adult cancer survivors. Support Care Cancer. 2009;17(4):349-357.

30. Hurria A, Li D, Hansen K, et al. Distress in older patients with cancer. J Clin Oncol. 2009;27(26):4346-4351.

31. U.S. Department of Health and Human Services. Healthy People 2010: Understanding and improving health. 2nd ed. Washington, DC: U.S. Government Printing Office; 2000.

32. Davis TC, Williams MV, Marin E, Parker RM, Glass J. Health literacy and cancer communication. CA Cancer J Clin. 2002;52(3):134-149.

33. Bosworth HB. Challenges and strategies to improve patient health literacy and competencies. Patient Intell. 2010;2:19-25.

34. Lindau ST, Tomori C, Lyons T, Langseth L, Bennett CL, Garcia P. The association of health literacy with cervical cancer prevention knowledge and health behaviors in a multiethnic cohort of women. Am J Obstet Gynecol. 2002;186(5):938-943.

35. Baker DW, Wolf MS, Feinglass J, Thompson JA, Gazmararian JA, Huang J. Health literacy and mortality among elderly persons. Arch Intern Med. 2007;167(14):1503-1509.

36. Williams MV, Davis T, Parker RM, Weiss BD. The role of health literacy in patient-physician communication. Fam Med. 2002;34(5): 383-389. 
37. Schillinger D, Piette J, Grumbach K, et al. Closing the loop: physician communication with diabetic patients who have low health literacy. Arch Intern Med. 2003;163(1):83-90.

38. Zachariae R, Pedersen CG, Jensen AB, Ehrnrooth E, Rossen PB, von der Maase $\mathrm{H}$. Association of percieved physician communication style with patient satisfaction, distress, cancer-related self efficacy, and perceived control over the disease. Br J Cancer. 2003;88(5):658-665.

39. Katki HA, Wacholder S, Solomon D, Castle P, Shiffman M. Risk estimation for the next generation of cervical cancer prevention programs. Lancet Oncol. 2009;10(11):1022-1023.

40. Braithwaite D, Emery J, Marteau T, Walter F. Lay understanding of familial risk of common chronic diseases: a systematic review and synthesis of qualitative research. Annals Family Med. 2004;2:583-594.

41. Irwin RS, Richardson ND. Patient-focused care: using the right tools. Chest. 2006;130 Suppl 1:72S-83S.

42. Lillie SE, Brewer NT, O’Neill SC, et al. Retention and use of breast cancer recurrence risk information from genomic tests: the role of health literacy. Cancer Epidemiol Biomarkers Prev. 2007;16(2):249-255.

43. Miller DP Jr, Brownlee CD, McCoy TP, Pignone MP. The effect of health literacy on knowledge and receipt of colorectal cancer screening: a survey study. BMJ Fam Pract. 2007;8:16.

44. Carney L, Jones L, Braddon F, Pullyblank AM, Dixon AR. A colorectal cancer patient focus group develops an information package. Ann R Coll Surg Engl. 2006;88(5):447-449.

45. Schwartzberg JG, Cowett A, van Geest J, Wolf MS. Communication techniques for patients with low health literacy: a survey of physicians, nurses, and pharmacists. Am J Health Behav. 2007;31 Suppl 1:S96-S104.

46. Gattellari M, Voigt KJ, Butow PN, Tattersall MH. When the treatment goal is not cure: are cancer patients equipped to make informed decisions? J Clin Oncol. 2002;20(2):503-513.

47. Hobbs JL. A dimensional analysis of patient-centered care. Nurs Res. 2009;58(1):52-62.

48. McQuellon RP, Wells M, Hoffman S, et al. Reducing distress in cancer patients with an orientation program. Psychooncology. 1998;7(3): 207-217.

49. Street RL Jr, Slee C, Kalauokalani DK, Dean DE, Tancredi DJ, Kravitz RL. Improving physician-patient communication about cancer pain with a tailored education-coaching intervention. Patient Educ Couns. 2010;80(1):42-47.

50. Nemeth LS, Neitert PJ, Ornstein SM. High performance for screening for colorectal cancer: a Practice Partner Research Network (PPRNet) case study. J Am Board Fam Med. 2009;22(2):141-146.

51. Lacovino V, Reesor K. Literature on interventions to address cancer patients' psychosocial needs: what does it tell us? J Psycosoc Oncol. 1997;15(2):47-71.

52. Meyer TJ, Mark MM. Effects of psychosocial interventions with adult cancer patients: a meta-analysis of randomized experiments. Health Psychol. 1995;14(2):101-108.

53. Velikova G, Booth L, Smith AB, et al. Measuring quality of life in routine oncology practice improves communication and patient well-being: a randomized controlled trial. J Clin Oncol. 2004;22(4):714-724.

54. Hawkes AL, Hughes KL, Hutchison SD, Chambers SK. Feasibility of brief psychological distress screening by a community-based telephone helpline for cancer patients and carers. BMC Cancer. 2010;10:14.

55. Lovejoy NC, Matteis M. Cognitive-behavioral interventions to manage depression in patients with cancer: research and theoretical initiatives. Cancer Nurs. 1997;20(3):155-167.

Patient Intelligence

\section{Publish your work in this journal}

Patient Intelligence is an international, peer-reviewed, open access journal that characterizes and measures the central role of patient behavior and intention in optimizing healthcare management in all areas of disease and complaint types. An improved understanding of patient intelligence coupled with predictive analysis helps an organization contribute more effectively to achieving better outcomes. Submit your manuscript here: http://www.dovepress.com/patient-intelligence-journal
56. Cathcart F. Psychological distress in patients with advanced cancer. Clin Med. 2006;6(2):148-150.

57. Osborn RL, Demoncada AC, Feuerstein M. Psychosocial interventions for depression, anxiety, and quality of life in cancer survivors: metaanalyses. Int J Psychiatry Med. 2006;36(1):13-34.

58. Wengstrom Y, Haggmark C, Forsberg C. Coping with radiation therapy: effects of a nursing intervention on coping ability for women with breast cancer. Int J Nurs Pract. 2001;7(1):8-15.

59. Ong LM, Visser MR, Lammes FB, van Der Velden J, Kuenen BC, de Haes JC. Effect of providing cancer patients with the audiotaped initial consultation on satisfaction, recall, and quality of life: a randomized, double-blind study. J Clin Oncol. 2000;18(16):3052-3060.

60. Volk RJ, Jibaja-Weiss ML, Hawley ST, et al. Entertainment education for prostate cancer screening: a randomized trial among primary care patients with low health literacy. Patient Educ Couns. 2008;73(3):482-489.

61. Shelby RA, Taylor KL, Kerner JF, Coleman E, Blum D. The role of community-based and philanthropic organizations in meeting cancer patient and caregiver needs. CA Cancer J Clin. 2002;52(4):229-246.

62. Thune-Boyle IC, Stygall JA, Keshtgar MR, Newman SP. Do religious/spiritual coping strategies affect illness adjustment in patients with cancer? A systematic review of the literature. Soc Sci Med. 2006;63(1):151-164.

63. Hoey LM, Ieropoli SC, White VM, Jefford M. Systematic review of peer-support programs for people with cancer. Patient Educ Couns. 2008;70(3):315-337.

64. Macvean ML, White VM, Sanson-Fisher R. One-to-one volunteer support programs for people with cancer: a review of the literature. Patient Educ Couns. 2008;70(1):10-24.

65. Coyne JC, Lepore SJ, Palmer SC. Efficacy of psychosocial interventions in cancer care: evidence is weaker than it first looks. Ann Behav Med. 2006;32(2):104-110.

66. Lepore SJ, Coyne JC. Psychological interventions for distress in cancer patients: a review of reviews. Ann Behav Med. 2006;32(2):85-92.

67. Andersen BL. Biobehavioral outcomes following psychological interventions for cancer patients. J Consult Clin Psychol. 2002;70(3): 590-610.

68. Montazeri A. Quality of life data as prognostic indicators of survival in cancer patients: an overview of the literature from 1982 to 2008. Health Qual Life Outcomes. 2009;7(1):102-123.

69. Thompson A, Brennan K, Cox A, et al. Evaluation of the current knowledge limitations in breast cancer research: a gap analysis. Breast Cancer Res. 2008;10(2):R26.

70. Fawzy FI, Fawzy NW, Hyun CS, et al. Malignant melanoma. Effects of an early structured psychiatric intervention, coping, and affective state on recurrence and survival 6 years later. Arch Gen Psychiatry. 1993; 50(9):681-689.

71. Lis CG, Gupta D, Grutsch JF. Patient satisfaction with quality of life as a predictor of survival in pancreatic cancer. Int J Gastrointest Cancer. 2006;37(1):35-44.

72. Stull VB, Snyder DC, Denmark-Wahnefried W. Lifestyle interventions in cancer survivors: designing programs that meet the needs of this vulnerable and growing population. J Nutr. 2007;137 Suppl 1: 243S-248S

The journal is characterized by the rapid reporting of reviews, original research, methodologies, analytics, modeling, clinical studies and patient surveys across all disease areas. The manuscript management system is completely online and includes a very quick and fair peer-review system. Visit http://www.dovepress.com/ testimonials.php to read real quotes from published authors. 